\title{
Anxiety level among students of different college and universities in India during lock down in connection to the COVID-19 pandemic
}

\author{
Saroni Biswas ${ }^{1} \cdot$ Anirban Biswas $^{2}$ \\ Received: 14 May 2020 / Accepted: 19 November 2020 / Published online: 7 January 2021 \\ (C) Springer-Verlag GmbH Germany, part of Springer Nature 2021
}

\begin{abstract}
Objectives COVID-19 incidence became a pandemic immediately after its origin and spread. Apart from death because of coronavirus infection, the pandemic brought unbearable psychological pressure to all. We assessed the psychological pressure on college and university students in India through cluster sampling.

Methods The students responded $(n=209)$ to an online questionnaire following the Generalized Anxiety Disorder Scale (GAD7) and Hamilton Anxiety Rating Scale (HAM-A) with some other basic information.

Results According to GAD-7 scoring, we found the respondent students had severe anxiety (1.44\%), moderately severe anxiety $(14.35 \%)$, moderate anxiety (36.36\%) and mild anxiety (47.85\%). Following HAM-A scoring, anxiety level among the students could be scaled as severe $(0.96 \%)$, high $(4.31 \%)$, moderate $(13.40 \%)$ and mild anxiety $(34.93 \%)$ level. Age of the students was a confounding factor ( $p=0.049$, HAM-A) of experiencing anxiety, students $<20$ years of age were more anxious. We found female students to be more anxious than the males following the HAM-A scoring tool. Academic delays $\left(\mathrm{R}^{2}=0.996, p=0.036\right)$ and impact on daily life $\left(\mathrm{R}^{2}=0.996, p=0.117\right)$ were positively associated with anxiety symptoms, while social support was marginally correlated $\left(\mathrm{R}^{2}=0.726, p=0.069\right)$ with the anxiety level.

Conclusions As the study found almost all the students are experiencing anxiety because of the current pandemic situation, continuous observation of psychological health for all is recommended as well as establishing psychological intervention during the preparedness phase.
\end{abstract}

Keywords Coronavirus · COVID-19 · Pandemic · Anxiety · GAD-7 · HAM-A

\section{Introduction}

The novel coronavirus (SARS-CoV-2 and its disease COVID19) spread started from Wuhan, Hubei Province of China in December 2019 (WHO 2020). Soon after the spread began, the WHO declared it a pandemic on 11 March 2020. COVID19 is an acute respiratory illness (Paules et al. 2020; Wang et al. 2020). As of 7 May 2020, approximately 3,862,709 confirmed cases and 267,121 deceased cases were recorded globally (worldometers.info), and India had 53,045 confirmed

Anirban Biswas

anirbanbsws@yahoo.co.in; anirban@nvc.ac.in

1 Department of Agricultural Meteorology and Physics, Bidhan Chandra Krishi Viswavidyalaya, Kalyani, West Bengal 741235, India

2 Departmernt of Environmental Science, Nabadwip Vidyasagar College, Nabadwip, West Bengal 741302, India cases and 1787 deceased cases (MoHFW 2020). In India, to fight against COVID-19, lockdown was declared w.e.f. 23 March 2020. It was also reported earlier that vulnerability could be felt due to global health threats that require physical control measures such as closure of all sectors expect for emergency services, maintaining social distance and home quarantine. Such measures lead to the loss of many livelihoods of the rural population, disruption in education pattern of schools, colleges and universities, work closures and suffering from medical emergencies due to other diseases (Taylor et al. 2010). Such physical measures have a psychological impact (Brooks et al. 2020). Authors anticipated this pandemic and lockdown in the country would cause stress for the entire population. It is also reported that mass disasters involving infectious disease often trigger waves of enhanced fear and anxiety that cause immense interference in the behaviour and psychological well-being of several populations (Balaratnasingam and Janca 2006; Chong et al. 2004; Wu et al. 2009; Wheaton et al. 2012; Liu et al. 2020). 
The circumstances of the COVID-19 pandemic, lockdown across the country and strict isolation and social distancing measures, delay in prevailing educational system viz. postponement of examinations, sudden closure of classes, etc., are expected to influence the mental health of the students of several schools, colleges and universities across the country. Several studies have reported on the psychological impact of the COVID-19 pandemic on the general public, health workers, patients, children and older adults (Chen et al. 2020; Yang et al. 2020; $\mathrm{Li}$ et al. 2020). Considering the COVID-19 lockdown, the authors have decided to evaluate the impact of the COVID-19 pandemic among the students of colleges and universities in India. It is the first attempt so far to evaluate the psychological consequences that the COVID-19 pandemic is having among the students of colleges and universities. Therefore, the Generalized Anxiety Disorder Scale (GAD-7), a seven items tool, was used to study the mental health status of college and university students. GAD-7 is one of the most widely used tools for identifying and screening of anxiety disorders and is also presented as a module of the Patient Healthcare Questionnaire (PHQ; Spitzer et al. 2006) which helps in diagnosis of specific disorders (Johnson et al. 2019; Moreno et al. 2019; Toussaint et al. 2020) and takes less than $3 \mathrm{~min}$ to complete and score easily (Budikayanti et al. 2019). Apart from GAD-7, another tool called Hamilton Anxiety Rating Scale (HAM-A) was also used, and it consists of 14 sets of questions that also helps in evaluating the anxiety level (both psychic anxiety and somatic anxiety) and takes 10 min to complete (Hamilton 1959; Maier et al. 1988; Borkovec and Costello 1993). However in our study we have considered only the psychic anxiety. Our present study mainly focused on evaluating the teaching learning pattern during the COVID-19 lockdown phase along with other activities and precautions occurred during lockdown; finally, the anxiety level was evaluated using GAD-7 and HAM-A.

\section{Materials and methods}

\section{Data collection}

The study was conducted based on cross-sectional observation. The survey was conducted through online forms, generated using Google platform, were initially circulated among known students and professors who further circulated the link through email and other social media. We received responses from 209 respondents. The questionnaire included some general information viz. age, academic level, institute/university, etc. A few questions were regarding the present status of teaching learning viz. normal study time (hr/day) at the institute and at home; whether attending online classes, are they depending upon some other sources to finish their syllabus, study time being at home during lockdown; experience regarding online classes; daily transport cost in usual time to go to the institutes and impact of lockdown on their studies. The next section was related to other activities performed during the COVID-19 lockdown, included 11 questions viz. whether involved in household chores; whether doing fitness workout; daily average screen time; do they feel any health problems from high screen time; time spent for creative activities; whether experienced any health issues during the COVID-19 lockdown period; whether they went out to collect essential goods; personal precautions taken when going out and at home separately; opinion on lockdown and if they have any input to the current situation .

The last section of the questionnaire included anxiety level scaling through GAD-7 comprising seven questions (PHQ; Spitzer et al. 2006). Included questions were: feeling nervous; continuous mental pressure; worrying too much about different things; does any work relax you; being restless; becoming easily annoyed; or irritated and feeling afraid. Each question had four options, namely — not at all; several days; more than half the days; nearly every day-with a four Likert scale of 0 , $1,2,3$, respectively. However, to make it simple for the students to understand, the general question four of GAD-7 'trouble relaxing' was modified to 'does any work relax you'. The score for this particular question was just the reverse of the Likert scale and accordingly scoring was done. The gradation of GAD-7 based upon the scores are 0 to $4=$ mild anxiety; 5 to $9=$ moderate anxiety; 10 to $14=$ moderately severe anxiety; 15 to $21=$ severe anxiety. To be more specific, another set of questions were prepared based on HAM-A which includes only psychic anxiety questions in our present study tool with a five Likert scale (Hamilton 1959). The gradation of HAM-A based upon the scores are 0 to 6 no anxiety, 7 to 13 mild anxiety, 14 to 19 moderate anxiety, 20 to 26 high anxiety, $>26$ severe anxiety. The questions were mainly on anxious mood; tension; fear; insomnia; intellectual; depressed mood; depressed because of not meeting friends in institutes/colleges/universities/localities; and depressed because of not going out. A few other questions included information regarding their perception on how their parents and friends support them to keep them happy; whether they are happy staying at home.

\section{Statistical analysis}

Descriptive statistics was used to illustrate the demographic characteristics as well as the general responses regarding COVID-19 by the respondents. The prevalence of GAD-7 and HAM-A was explored through univariate nonparametric analysis (Kruskal Wallis test) and the significance of the association between the anxiety level during COVID-19 and demographic characteristics were performed. COVID-19 related stressors were identified as academic delays, social support and impact on daily life. The association between the stressors and anxiety level was assessed 
through correlation analysis. In all analyses, $p$ value less than 0.05 was considered as significant. Data were analysed with MINITAB 14.

\section{Results}

\section{Impact of COVID-19 lockdown on learning process of students}

We received 209 responses from the students of nongovernment $(164,78.47 \%)$ and government institutions $(45,21.53 \%)$. The average age of the students is $20.33 \pm$ 2.00. We obtained more responses from the female (183, $87.56 \%)$ students than the male $(26,12.44 \%)$. From the study, it was revealed that in normal days the study hour per day for most of the students $(133,63.64 \%)$ lies between two to four hours/day, while during the lockdown phase $56.94 \%$ (119) participants study at home for two to four hours. On the other hand, the participants who responded $(4.78 \%)$ that usually their study time ranges from less than two hours, could increase to $11.48 \%$, similarly the participants whose study hours per day ranges from five to seven hours a day, has increased to approximately $25.36 \%$. It was also observed that $3.35 \%$ (7) of participants usually study more than eight hours, while during lockdown the percent increased to $6.22 \%$ (Table 1). Of participants, $73.21 \%$ (153) usually attend college/institute/universities for six to eight hours daily. In many institutes, online classes were arranged to cover the semester syllabus, and $79.43 \%$ (166) of students were attending them regularly. However, to cover their syllabus and gather knowledge on subjects, students also rely on different means of study viz. group discussion among friends over video conference $(2.87 \%, 6)$; other online resources $(45.45 \%, 95)$ and both by $27.27 \%$ (57). Approximately $17.70 \%$ (37) of students were negative toward the online classes, but $72.25 \%$ (151) of the students enjoyed the changes with good experiences. Severe impact on their studies due to lockdown was reported by $9.09 \%$ (19 students), followed by $32.54 \%$ high impact (68 students) and $47.37 \%$ moderate impact (99 students). Approximately $11 \%$ (23) of students found no impact on their studies (Table 1). Information regarding daily transport cost to reach the institute were also recorded which revealed that $57.42 \%$ (120) of students have daily expenses for transport to reach their institute (mean: 40.25 \pm 39.57 , range Rs. $10-600$ ). However, $42.58 \%$ (89) of students did not have any transportation cost to reach their institute. For the first category of students, due to lockdown, the daily transport cost was a saving to their family which approximately ranges from Rs. 800 to Rs. 48,000 (considering 80 days of institutional lockdown, till 10 June as declared).
Table 1 Responses of participants regarding the education system during the COVID-19 lockdown phase

\begin{tabular}{lc}
\hline Particulars/items & Percent of responses (n) \\
\hline What is your normal study time (hr/day) at home on usual days? \\
Less than 2 h & $4.78(10)$ \\
2 to 4 h & $63.64(133)$ \\
5 to 7 h & $28.23(59)$ \\
More than 8 h & $3.35(7)$ \\
What is your normal study time (hr/day) at institute on usual days? & $2.39(5)$ \\
Less than 3 h & $24.40(51)$ \\
3 to 5 h & $73.21(153)$ \\
6 to 8 h & $79.43(166)$ \\
Are you attending online classes from home? & $2.87(6)$ \\
Are you depending on any other means to finish the course or syllabus? \\
GD & $45.45(95)$ \\
Online sources & $27.27(57)$ \\
Both & $24.40(51)$ \\
None & \\
Your study time being at home during lockdown \\
Less than 2 h & $11.48(24)$ \\
2 to 4 h & $56.94(119)$ \\
5 to 7 h & $25.36(53)$ \\
More than 8 h & $6.22(19)$ \\
Your experience of online classes & \\
No difference from class & $10.05(21)$ \\
Good & $72.25(151)$ \\
It is unwanted & $17.70(37)$ \\
Nompact on your study during lockdown & \\
Moderate & $11.00(23)$ \\
High & $47.37(99)$ \\
\hline & \\
\hline
\end{tabular}

\section{Impact of the COVID-19 lockdown on other activities of the students}

Being at home for long time, besides regular study and attending online classes, $81.82 \%$ (171) of students were involved in household chores; $69.86 \%$ (146) of students could manage time for fitness work out; and $85.65 \%$ (179) of the students enjoyed creative activities, mainly spending time on their hobbies such as painting, book reading, music and crafts. Owing to staying home, students' attachment to laptop and mobiles increased significantly. More than two hours of screen time was observed in $88 \%$ (184) of the students. Mean screen time was $5.52 \pm 3.06 \mathrm{~h} /$ day. Owing to high screen time per day, $83 \%$ (173) of students were found to suffer from different health issues (both direct and associated) viz. headache $(35.89 \%, 75)$, sleeping disorder $(26.32 \%, 55)$, 
cramp while walking $(4.78 \%, 10)$, eye irritation $(34.45 \%, 32)$, back pain $(14.83 \%, 31)$ and shoulder pain $(9.57 \%, 20)$ (Table 2).

Of the students, $50.24 \%$ (105) had to go to the market during lockdown phase to collect essential goods for their family. It was recorded that $96.17 \%$ (201) of them used a mask while going out, and after returning home, $72.73 \%$ (152) used soap for washing and 75.12\% (157) used sanitizer. Students were found to take their own precautionary measures being at home such as $48.33 \%$ (101) of students washed their hands with soap frequently, $6.22 \%$ (13) used only sanitizer and $45.45 \%$ (95) used both the items. All the participants were asked to impart their view on lockdown for fighting COVID-
19 and all of them were well aware of the facts and said it was of necessity; $52.63 \%$ (110) students took it as a wise decision, $38.28 \%$ (80) said it was good and $8.61 \%$ (18) found it satisfactory (Table 2).

\section{Psychological impact of COVID-19 on students}

Regarding the psychological impact of COVID-19, the anxiety levels of the students were assessed based upon two questionnaire tools, GAD-7 and HAM-A. The maximum and minimum score for GAD-7 were recorded as 19 and 0, respectively, while the same according to HAM-A was found to be 30 and 0 , respectively. According to GAD-7 scoring, we found
Table 2 Responses of participants related to other activities, precautions taken for COVID-19 and their view on the COVID19 lockdown

\section{Particulars/items}

Percent of responses (n)

Are you involved in household work?, if yes mention the approx hour/s

$81.82(171)$

Are you doing a health fitness workout?

$69.86(146)$

Are you feeling any health problems from high screen time?

Headache

$35.89(75)$

Sleeping disorder

26.32 (55)

Cramp while walking

4.78 (10)

Eye irritation

34.45 (72)

Back pain

14.83 (31)

Shoulder pain

9.57 (20)

None

25.36 (53)

Are you spending time on creative work or hobbies?

$85.65(179)$

Got any health issues during COVID-19 lockdown period and anxiety?

Sleepless night

$33.01(69)$

Sleeping disorder

$34.45(72)$

Headache

$35.41(74)$

Mental stress

$53.11(111)$

Others

$14.35(30)$

Did you go to market during lockdown period for foods and other essential services?

$50.24(105)$

Personal precautions taken for COVID-19 when going out

Wearing mask

$96.17(201)$

Washing hand with soap after return

$72.73(152)$

Using sanitizer

$75.12(157)$

Personal precautions are taken for COVID-19 when at home

Washing hand with soap

$48.33(101)$

Using sanitizer

$6.22(13)$

Both

$45.45(95)$

Your opinion on lockdown for fighting COVID-19

$\begin{array}{lr}\text { Not necessary } & 0.48(1) \\ \text { Satisfactory } & 8.61(18) \\ \text { Good } & 38.28(80) \\ \text { Wise } & 52.63(110) \\ \text { Did you make any contribution to anyone during this situation? } & 70.33(147)\end{array}$


Table 3 Age and gender wise psychological impact of COVID-19 on students (percent respondents)

GAD-7 \% respondents (n)

\begin{tabular}{|c|c|c|c|c|c|c|c|c|}
\hline Age & Mean (SD) & Mild anxiety & Moderate anxiety & Moderately severe anxiety & \multicolumn{2}{|l|}{ Severe anxiety } & Statistics & $p$ value \\
\hline$<20$ years & $5.86(3.61)$ & $51.28(40)$ & $33.33(26)$ & $15.38(12)$ & \multicolumn{2}{|l|}{$0.00(0)$} & 0.33 & 0.561 \\
\hline$\geq 20$ years & $6.24(3.62)$ & $45.80(60)$ & $38.17(50)$ & $13.74(18)$ & \multicolumn{2}{|l|}{$2.29(3)$} & & \\
\hline \multicolumn{9}{|l|}{ Gender } \\
\hline Female & $6.19(3.62)$ & $49.18(90)$ & $33.33(61)$ & $15.85(29)$ & \multicolumn{2}{|l|}{$1.64(3)$} & 0.14 & 0.701 \\
\hline Male & $5.38(3.62)$ & $38.46(10)$ & $57.69(15)$ & $3.85(1)$ & \multicolumn{2}{|l|}{$0.00(0)$} & & \\
\hline \multicolumn{9}{|c|}{ HAM-A \% respondents (n) } \\
\hline Age & Mean (SD) & Normal & Mild anxiety & Moderate anxiety & High anxiety & Severe anxiety & & \\
\hline$<20$ years & $6.92(5.86)$ & $53.85(42)$ & $32.05(25)$ & $0.00(0)$ & $8.97(7)$ & $5.13(4)$ & 3.87 & 0.049 \\
\hline$\geq 20$ years & $8.54(6.03)$ & $41.98(55)$ & $36.64(48)$ & $16.03(21)$ & $3.82(5)$ & $1.53(2)$ & & \\
\hline \multicolumn{9}{|l|}{ Gender } \\
\hline Female & $7.74(6.03)$ & $49.72(91)$ & $31.15(57)$ & $13.66(25)$ & $4.37(8)$ & $1.09(2)$ & 4.97 & 0.026 \\
\hline Male & $9.30(5.86)$ & $23.07(6)$ & $61.54(16)$ & $11.54(3)$ & $3.85(0)$ & $0.00(0)$ & & \\
\hline
\end{tabular}

the student respondents with severe anxiety $(1.44 \%, 3)$, moderately severe anxiety $(14.35 \%, 30)$, moderate anxiety $(36.36 \%, 76)$ and mild anxiety $(47.85 \%, 100)$. Following HAM-A scoring, the experienced anxiety levels among the students were found to be scaled as severe $(0.96 \%, 2)$, high $(4.31 \%, 9)$, moderate $(13.40 \%, 28)$ and mild anxiety $(34.93 \%$, 73) level. Students' anxiety level was estimated depending their age class viz. $<20$ years and $\geq 20$ years. The mean values of anxiety through the tool GAD-7 for age classes $<20$ years and $\geq 20$ years were $4.75 \pm 5.38$ and $5.68 \pm 5.89$, respectively, leading to mild anxiety level for all the students. As per the score, only $2.29 \%$ (3) students were suffering from severe anxiety in the $\geq 20$ years age class. According to GAD- 7 , the age class $<20$ years was recorded to have moderately severe anxiety, moderate anxiety and mild anxiety level for $15.38 \%$ (12), $33.33 \%$ (26) and $51.28 \%$ (40), respectively. Similarly for age class $\geq 20$ years, the observed anxiety level trend was found as severe anxiety $(2.29 \%, 3)<$ moderately severe anxiety $(13.74 \%, 18)<$ moderate anxiety $(38.17 \%, 50)$ and mild anxiety $(45.80 \%, 60)$. The results showed an indifferent level of anxiety between the two age classes of students $(\mathrm{H}=0.33$, $p=0.561$ ) following GAD-7 data (Table 3).

According to HAM-A scoring, the mean anxiety level for the age classes $<20$ years and $\geq 20$ years was $6.92 \pm 5.86$ and $8.54 \pm 6.03$, depicting mild anxiety level for all the students. Of students in the age class $<20$ years, $46.15 \%$ (36) were found to be anxious, indicating mild anxiety $(32.05 \%, 25)$, high anxiety $(8.97 \%, 7)$ and severe anxiety $(5.13 \%, 4)$. In the age class $\geq 20$ years, $58.02 \%$ (76) of students were anxious, with mild $(36.64 \%, 48)$, moderate $(16.03 \%, 21)$, high $(3.82 \%$, $5)$ and severe anxiety $(1.53 \%, 2)$. According to the HAM-A scoring tool, we found a significant difference $(\mathrm{H}=3.87, p=$ 0.049 ) of anxiety level considering age as a confounding factor (Table 3).
Following GAD-7 scoring, we found no difference in $(\mathrm{H}=$ $0.14, p=0.701)$ anxiety level among male and female students, where $50.82 \%$ (93) of female and only $61.54 \%$ (16) of male students were under moderate to severe anxiety. However, as per the HAM-A scoring, we found significantly different $(\mathrm{H}=4.97, p=0.026)$ anxiety levels between female and male students, where $58.02 \%$ (92) of female (mild $31.15 \%, 57$; moderate $-13.66 \%, 25$; high $-4.37 \%$, 8 ; severe $-1.53 \%, 2$ ) and $76.93 \%$ (20) of male (mild $-61.54 \%, 16$; moderate $-11.54 \%, 3$; high $-3.85 \%, 1)$ students were anxious (Table 3).

Expected COVID-19 related stressors and student anxiety level was correlated (Table 4). The analysis showed that students were really worried about the academic process delays $\left(\mathrm{R}^{2}=0.996, p=0.036\right)$ for which their study was affected. We also found that students are little worried $\left(\mathrm{R}^{2}=0.726, p=\right.$ 0.069 ) about their social support during the lockdown period, because they had to maintain the social distancing from friends and sometimes from family members as well. In this case, although the data was not statistically significant, we could conclude it from the answered questionnaire. Surprisingly, we found no significant effect $\left(\mathrm{R}^{2}=0.726, p=\right.$ 0.069) of the lockdown on the students' daily life.

Table 4 Correlation and regression analysis between the COVID-19related stressors and students anxiety

\begin{tabular}{lll}
\hline Stressor & $p$ value & $\mathrm{R}^{2}$ \\
\hline Academic delays/impact on studies & 0.036 & 0.996 \\
Social support & 0.069 & 0.726 \\
Influence on daily life & 0.117 & 0.996 \\
\hline
\end{tabular}




\section{Discussion}

As per our survey, following the GAD-7 tool, $15.79 \%$ of college and university students (irrespective of age class) were anxious because of the COVID-19 pandemic, where $>9$ score was considered for experiencing anxiety. This was contributed by moderately severe and severe anxiety with $14.35 \%$ and $1.44 \%$, respectively. Previous studies suggested that emergencies in public health can have several psychological effects on college/university students, expressed mainly as anxiety, fear and worry among others (Mei et al. 2011). When age class was segregated, the percent of experienced anxiety among the students for $<20$ years were found to be $15.38 \%$ contributing towards moderately severe anxiety (Table 3 ). Age class $\geq 20$ years have experienced anxiety level among $16.03 \%$ ( $13.74 \%$ moderately severe anxiety; $2.29 \%$ severe anxiety). According to HAM-A scoring, 55.03\% students experienced an anxiety level which is mild to severe, where mild, moderate, high and severe anxiety level was found among $34.93 \%$, $14.83 \%, 4.31 \%$ and $0.96 \%$ students, respectively (Table 3). When assessed in different age classes following the HAM-A tool, it was found that $46.15 \%$ and $58.02 \%$ students were experiencing anxiety due to COVID-19 outbreak following age class $<20$ years and $\geq 20$ years, respectively.

It was seen that anxiety among the college/university students due to the COVID-19 pandemic is actually related to several issues, such as the effect of the lockdown on their studies and being late in any future planning (Cornine 2020; Wang et al. 2020) and an increase of social distancing between friends and even among family members which results in worsened mental situation (Xiao 2020; Kmietowicz 2020). Apart from these issues, the increased rates of number of positive cases in different parts of the country as well as sensational news headlines and reports have enhanced the distress among the public, including students (Bao et al. 2020; Ayittey et al. 2020). However, staying at home along with their parents proved to be one of the factors against anxiety as most of the students (82.78\%) feel happy staying at home and $89 \%$ of students feel their parents are supporting them mentally to keep them happy. Similar study results were reported by other researchers (Gentili et al. 2020). While attempting to understand the impact of the COVID-19 lockdown on the learning process of students, it was observed that a smaller percentage of the students were maintaining their usual daily study time, which may be due to staying at home for long days. Many of the students were also found to be involved in several other activities such as household chores, fitness workout, spending time at their hobbies which for many of them was not always possible to manage under their regular schedule.

As one of the objectives of the current paper to determine the COVID-19-related stressors, academic delays was positively associated $\left(\mathrm{R}^{2}=0.996, p=0.036\right)$ with anxiety symptoms of the college/university students. In a very recent study among Chinese students, academic delays and social support were found highly correlated with students' anxiety level (Cao et al. 2020), and it has been seen in our study also. With an epidemic emergency, there will be short falls in economic growth that directly or indirectly affect students' education and further career development which creates anxiety among them (Kernan 2019). In the present study, social support was marginally correlated $\left(\mathrm{R}^{2}=0.726, p=0.069\right)$ with the anxiety of college students, which is consistent with previous findings (Thompson et al. 2016; Chen et al. 2020). At any point of time, especially during the COVID-19 pandemic, social support reduces the psychological pressure of the students (Bai et al. 2005) and changes their attitude to deal with any emergency for the future. The pandemic related lockdown created enormous metal pressure for the college/university students and influenced their daily life. These results suggest that effective and robust social support is necessary during public health study emergencies for their proper future development.

\section{Conclusion}

Applying different anxiety level scoring methods, we found that $15.79 \%$ (GAD-7: score >9) and $53.60 \%$ (HAM-A: score $>6$ ) of the college and university students in India were experiencing anxiety due to the COVID-19 pandemic and lockdown. Age of the students was a confounding factor of experiencing anxiety, students $<20$ years of age were more anxious. We found female students to be more anxious than the males following the HAM-A scoring tool. Among various stressors of the COVID-19 pandemic, we found students' anxiety maximum for their academics such as delayed examination schedule and unfinished syllabus. Students also needed enormous social support from family and friends because social support reduces the psychological pressure of the students.

Acknowledgements We highly acknowledge the students who participated in the study.

Authorship contribution Equal contribution was made by both the authors.

\section{Compliance with ethical standards}

Conflict of interest The authors declare no conflict of interest.

\section{References}

Ayittey FK, Ayittey MK, Chiwero NB, Kamasah JS, Dzuvor C (2020) Economic impacts of Wuhan 2019-nCoV on China and the world. J Med Virol. https://doi.org/10.1002/jmv.25706

Bai YX, Gegan T, Hai H, Liu ZH, Wang WR, Wang ZG (2005) Correlation between psychological changes of the community 
crowd and the social support in grave public health event. Inner Mongolia Med J 37(04):295-297

Balaratnasingam S, Janca A (2006) Mass hysteria revisited. Curr Opin Psychiatry 19:171-174

Bao Y, Sun Y, Meng S, Shi J, Lu L (2020) 2019-nCoV epidemic: address mental health care to empower society. Lancet 395(10224):e37-e38

Borkovec T, Costello E (1993) Efficacy of applied relaxation and cognitive behavioral therapy in the treatment of generalized anxiety disorder. J Clin Consult Psychol 61(4):611-619

Brooks SK, Webster RK, Smith LE, Woodland L, Wessely S, Greenberg N, Rubin GJ (2020) The psychological impact of quarantine and how to reduce it: rapid review of the evidence. Lancet 395:912-920

Budikayanti A, Larasari A, Malik K, Syeban Z, Indrawati LA, Octaviana F (2019) Screening of generalized anxiety disorder in patients with epilepsy: using a valid and reliable Indonesian version of generalized anxiety disorder-7 (GAD-7). Neurol Res Int 5902610. https:// doi.org/10.1155/2019/5902610

Cao W, Fang Z, Hou G, Han M, Xu X, Dong J, Zheng J (2020) The psychological impact of the COVID-19 epidemic on college students in China. Psychiatry Res. https://doi.org/10.1016/j.psychres. 2020.112934

Chen Q, Liang M, Li Y, Guo J, Fei D, Wang L, He L, Sheng C, Cai Y, Li X, Wang J, Zhang Z (2020) Mental health care for medical staff in China during the COVID-19 outbreak. Lancet Psychiatry. https:// doi.org/10.1016/S2215-0366(20)30078-X

Chong M, Wang W, Hsieh W, Lee C, Chiu N, Yeh W, Huang T, Wen J, Chen C (2004) Psychological impact of severe acute respiratory syndrome on health workers in a tertiary hospital. Br J Psychiatry 185(2):127-133. https://doi.org/10.1192/bjp.185.2.127

Cornine A (2020) Reducing nursing student anxiety in the clinical setting: an integrative review. Nurs Educ Perspect 10. https://doi.org/10. 1097/01.NEP.0000000000000633

Gentili D, Bardin A, Ros E, Piovesan C, Ramigni M, Dalmanzio M, Dettori M, Filia A, Cinquetti S (2020) Impact of communication measures implemented during a school tuberculosis outbreak on risk perception among parents and school staff, Italy. Int J Environ Res Public Health 17(3):E911. https://doi.org/10.3390/ijerph17030911

Hamilton M (1959) The assessment of anxiety states by rating. Br J Med Psychol 32:50-55

Johnson SU, Ulvenes PG, Øktedalen T (2019) Psychometric properties of the general anxiety disorder 7-item (GAD-7) scale in a heterogeneous psychiatric sample. Front Psychol 10:1713. https://doi.org/ 10.3389/fpsyg.2019.01713

Kernan WD (2019) Health-related impediments to learning among dental and oral surgery students. J Prev Interv Community 47(1):32-44

Kmietowicz Z (2020) Rules on isolation rooms for suspected covid-19 cases in GP surgeries to be relaxed. BMJ 368:m707. https://doi.org/ 10.1136/bmj.m707

Li SW, Wang Y, Yang YY, Lei XM, Yang YF (2020) Analysis of influencing factors of anxiety and emotional disorders in children and adolescents during home isolation during the epidemic of novel coronavirus pneumonia. Chin J Child Health:1-9

Liu S, Yang L, Zhang C, Xiang Y, Liu Z, Hu S, Zhang B (2020) Online mental health services in China during the COVID-19 outbreak. Lancet Psychiatry 7(4):e17-e18. https://doi.org/10.1016/S22150366(20)30077-8
Maier W, Buller R, Philipp M, Heuser I (1988) The Hamilton anxiety scale: reliability, validity and sensitivity to change in anxiety and depressive disorders. J Affect Disord 14(1):61-68

Mei SL, Yu JX, He BW, Li JY (2011) Psychological investigation of university students in a university in Jilin province. Med Soc (Berkeley) 24(05):84-86

MoHFW (2020) https://www.mohfw.gov.in/. Accessed on 3 May 2020. IST 10:00 PM

Moreno E, Muñoz-Navarro R, Medrano LA, González-Blanch C, RuizRodríguez P, Limonero JT, Moretti LS, Cano-Vindel A, Moriana JA (2019) Factorial invariance of a computerized version of the GAD-7 across various demographic groups and over time in primary care patients. J Affect Disord 252:114-121

Paules CI, Marston HD, Fauci AS (2020) Coronavirus infections - more than just the common cold. JAMA 323:707-708. https://doi.org/10. 1001/jama.2020.0757

Spitzer RL, Kroenke K, Williams JB, Lowe B (2006) A brief measure for assessing generalized anxiety disorder: the GAD-7. Arch Intern Med 166:1092-1097. https://doi.org/10.1001/archinte.166.10.1092

Taylor M, Barr M, Stevens G, Bryson-Taylor D, Agho K, Jacobs J, Raphael B (2010) Psychosocial stress and strategies for managing adversity: measuring population resilience in New South Wales, Australia. Popul Health Metrics 14(8):28. https://doi.org/10.1186/ 1478-7954-8-28.

Thompson G, McBride RB, Hosford CC, Halaas G (2016) Resilience among medical students: the role of coping style and social support. Teach Learn Med 28(2):174-182

Toussaint A, Hüsing P, Gumz A, Wingenfeld K, Härter M, Schramm E, Löwe B (2020) Sensitivity to change and minimal clinically important difference of the 7-item generalized anxiety disorder questionnaire (GAD-7). J Affect Disord 265:395-401

Wang D, Hu B, Hu C, Zhu F, Liu X, Zhang J, Wang B, Xiang H, Cheng Z, Xiong Y, Zhao Y, Li Y, Wang X, Peng Z (2020) Clinical characteristics of 138 hospitalized patients with 2019 novel coronavirusinfected pneumonia in Wuhan, China. JAMA 323:1061-1096. https://doi.org/10.1001/jama.2020.1585

Wheaton MG, Abramowitz JS, Berman NC, Fabricant LE, Olatunji BO (2012) Psychological predictors of anxiety in response to the H1N1 (swine flu) pandemic. Cogn Ther Res 36(3):210-218. https://doi. org/10.1007/s10608-011-9353-3

World Health Organization (2020) Novel coronavirus (2019-nCoV): situation report. Accessed 2 May 2020. https://www.who.int/docs/ default-source/coronaviruse/situationreports

Wu P, Fang Y, Guan Z, Fan B, Kong J, Yao Z, Liu X, Hoven CW (2009) The psychological impact of the SARS epidemic on hospital employees in China: exposure, risk perception, and altruistic acceptance of risk. Can J Psychiatr 54:302-311

Xiao C (2020) A novel approach of consultation on 2019 novel coronavirus (COVID-19)- related psychological and mental problems: structured letter therapy. Psychiatry Investig 17(2):175-176

Yang Y, Li W, Zhang Q, Zhang L, Cheung T, Xiang YT (2020) Mental health services for older adults in China during the COVID-19 outbreak. Lancet Psychiatry 4:E19. https://doi.org/10.1016/S22150366(20)30079-1

Publisher's note Springer Nature remains neutral with regard to jurisdictional claims in published maps and institutional affiliations. 